\title{
Bactérias psicrotróficas e atividade proteolítica no leite cru refrigerado
}

\author{
Psychrotrophic bacteria and proteolytic activity in refrigerated raw milk
}

Maria de Fátima Barros Leal Nörnberg ${ }^{1}$, Eduardo César Tondo ${ }^{2} \&$ Adriano Brandelli² $^{2}$

\begin{abstract}
RESUMO
O resfriamento prolongado do leite na fazenda, e a posterior coleta e transporte do produto em caminhões tanque isotérmicos pode possibilitar o desenvolvimento de micro-organismos psicrotróficos. Estes microrganismos, conhecidos pela sua habilidade em se desenvolver a temperaturas menores do que $7^{\circ} \mathrm{C}$, geralmente são eliminados pelos tratamentos térmicos aplicados ao leite, ao contrário de algumas de suas enzimas proteolíticas e lipolíticas, as quais resistem até mesmo ao tratamento UAT. Neste trabalho, foram determinadas contagens de bactérias psicrotróficas e atividade proteolítica de amostras de leite cru refrigerado obtidas de dois laticínios. As contagens médias foram entre 6,0 e 6,5 $\log \mathrm{UFC} / \mathrm{mL}$, não existindo diferenças significativas entre as duas plantas. Houve grande variabilidade na atividade proteolítica das amostras, existindo diferença significativa entre valores médios das duas plantas. Não houve correlação entre atividade proteolítica e contagens de psicrotróficos, sugerindo que a proteólise está associada a linhagens específicas de bactérias. Recentemente, a Instrução Normativa 51 estabeleceu que o leite deve ser refrigerado e armazenado na propriedade rural, aumentando a importância prática e industrial desse grupo de bactérias. Com a substituição do leite cru tipo $\mathrm{C}$ pelo leite cru refrigerado, o qual deve ser resfriado na propriedade e pode ter até $5,87 \log \mathrm{UFC} / \mathrm{mL}$ de mesófilos totais no momento de seu recebimento na usina, a preocupação sobre o grupo dos psicrotróficos aumenta ainda mais no mercado laticinista brasileiro.
\end{abstract}

Descritores: leite, refrigeração, protease, bactérias.

\section{ABSTRACT}

The prolonged milk refrigeration in the dairy farm and its transport in insulated containers on trucks, has given products with lower quality standards since prolonged refrigeration allow the development of psychrotrophic micro-organisms. These micro-organisms, known by their ability to develop at temperatures lower than $7^{\circ} \mathrm{C}$, are normally eliminated through heating treatments applied to milk, on contrast to their proteolytic and lipolytic enzymes, which often withstand even UHT treatments. In this work, psychrotrophic counts and proteolytic activity of raw milk samples from two dairy plants were determined. The average counts were between 6.0 and $6.5 \log \mathrm{CFU} / \mathrm{mL}$, without significant differences between the dairy plants. Proteolytic activity varies greatly among samples, and a significant difference was observed between the mean values of both dairy plants. A correlation between proteolytic activity and psychrotrophic counts was not observed, suggesting that proteolysis is associated with specific bacterial strains. Recently, Normative Instruction 51 has established that milk should be refrigerated and stored on the dairy farm thus increasing the practical and industrial importance of this group of bacteria. Raw milk type $\mathrm{C}$ has been substituted by refrigerated raw milk, which should be refrigerated on the dairy farm and could present up to $5,87 \log \mathrm{CFU} / \mathrm{mL}$ of total mesophiles at the moment it is received at the dairy plant. Thus, the presence of psychrotrophics becomes an issue of greater concern within the Brazilian dairy market.

Keywords: milk, refrigeration, protease, bacteria.

${ }^{1}$ Departamento de Tecnologia e Ciência de Alimentos, Centro de Ciências Rurais, Universidade Federal de Santa Maria (UFSM), Santa Maria, RS, Brasil. 'Instituto de Ciência e Tecnologia de Alimentos, Universidade Federal do Rio Grande do Sul (UFRGS), 91501-970 Porto Alegre, RS, Brasil. CORRESPONDÊNCIA: M.F.B.L. Nörnberg [mflberg@smail.ufsm.br]. 


\section{INTRODUÇÃO}

$\mathrm{O}$ armazenamento do leite cru sob refrigeração possibilita a redução de custos operacionais de produção e evita perdas dessa matéria-prima pela atividade acidificante de bactérias mesofílicas. Entretanto, o armazenamento por períodos prolongados pode resultar em queda de qualidade dos produtos lácteos, devido ao crescimento e à atividade enzimá-tica de bactérias psicrotróficas [7,19].

Embora representando menos $10 \%$ da microbiota inicial em condições sanitárias adequadas, a população de micro-organismos psicrotróficos no leite cru pode alcançar elevadas concentrações em condições mais precárias de higiene [7,30]. Este é um fato preocupante, pois, embora a grande maioria seja destruída pela pasteurização, os psicrotróficos são capazes de produzir enzimas lipolíticas e proteolíticas termorresistentes, que mantêm sua atividade após a pasteurização ou mesmo após o tratamento por UAT (Ultra-Alta Temperatura). Alguns problemas relacionados à qualidade dos produtos lácteos, como alteração de sabor e odor do leite, perda de consistência e gelatinização ao longo da vida comercial do leite UAT, podem estar associados à ação de proteases e lipases de origem bacteriana $[4,31,33]$. A gelatinização constitui-se num dos principais problemas que afetam a qualidade do leite UAT. Alguns pesquisadores acreditam que esta é induzida, inicialmente, pela ação de proteases termorresistentes presentes naturalmente no leite e/ou provenientes de bactérias, principalmente do grupo dos psicrotróficos $[16,18]$. Estas enzimas apresentam a capacidade de degradar as caseínas e promover a agregação das micelas do leite $[8,30]$. Parece imprudente a fabricação de produtos a partir do leite em que a contagem de psicrotróficos tenha excedido a $6 \mathrm{log}$ UFC/mL, pois, nesse caso, é grande a possibilidade da presença de enzimas hidrolíticas extracelulares [19,23].

A implementação do armazenamento do leite cru refrigerado na fonte de produção iniciou-se, no Brasil, na década de 90 do século XX, sendo regulamentada pela publicação da Instrução Normativa 51, do Ministério da Agricultura, Pecuária e Abastecimento, de 18 de setembro de 2002, que entrou em vigor em $1^{\circ}$ de julho de 2005, nas regiões sul, sudeste e centrooeste [2]. Nesse processo de conservação do leite pelo frio, recomenda-se que, na segunda hora após a ordenha, a temperatura deva estar a $4^{\circ} \mathrm{C}$, condição esta que pode favorecer a proliferação de micro-organismos psicro-tróficos [23]. Na maioria das propriedades leiteiras, a temperatura de refrigeração oscila de 5 a $10^{\circ} \mathrm{C}$, o que configura um resfriamento marginal do leite, contribuindo para multiplicação de micro-organismos psi-crotróficos [27]. Mesmo nas temperaturas de refrigeração propostas pela legislação brasileira para a conservação do leite no estabelecimento industrial, pode ocorrer perda de qualidade da matéria-prima se um controle efetivo de contaminação inicial não for realizado [18].

Neste artigo investigam-se a presença de bactérias psicrotróficas em amostras de leite cru refrigerado de dois laticínios do Rio Grande do Sul e sua correlação com a atividade proteolítica detectada nestas amostras. São discutidos os aspectos relacionados com a presença de bactérias psicrotróficas e proteolíticas no leite cru refrigerado e suas consequuências para a qualidade do leite e produtos lácteos.

Tabela 1. Valores médios de contagens de bactérias psicrotróficas e atividade proteolítica em leite cru refrigerado obtido de dois laticínios do Estado do Rio Grande do Sul.

\begin{tabular}{lccc} 
Laticínio $^{\mathbf{a}}$ & $\mathbf{n}$ & ${\text { Psicrotróficos totais }(\log \mathbf{U F C} / \mathbf{m L})^{\mathbf{b}}}$ & ${\text { Atividade proteolítica }(\mathbf{U} / \mathbf{m L})^{\mathbf{c}}}^{\text {L1 }}$ \\
\hline & 50 & $6,43 \pm 0,35$ & $12,3 \pm 9,1$ \\
L2 A & 20 & $6,36 \pm 0,78$ & $4,3 \pm 7,3$ \\
L3 B & 20 & $6,24 \pm 0,63$ & $3,3 \pm 5,2$ \\
\hline
\end{tabular}

${ }^{\mathrm{a}}$ Foram coletadas 50 amostras do silo de armazenamento do laticínio L1, 20 amostras do tanque isotérmico de caminhões (A) e 20 amostras do silo de armazenamento (B) do estabelecimento L2. ${ }^{\text {}}$ Contagens de psicrotróficos determinadas em placas de PCA incubadas por 10 dias a $7^{\circ} \mathrm{C}$. ${ }^{\mathrm{c}}$ Atividade proteolítica determinada pela hidrólise de gelatina solúvel [15]. 


\section{MATERIAIS E MÉTODOS}

Amostras de leite cru refrigerado foram coletadas de dois laticínios do Estado do Rio Grande do Sul. Foram coletadas 50 amostras do silo de armazenamento do primeiro laticínio (L1), durante o ano de 2005, e 20 amostras do tanque isotérmico de caminhões e 20 amostras do silo de armazenamento do segundo estabelecimento (L2), durante 2006. Amostras de 100 $\mathrm{mL}$ foram coletadas em frascos esté-reis e transportados a $7^{\circ} \mathrm{C}$, imediatamente ao laboratório.

As amostras foram submetidas a diluições seriadas até $10^{-8}$ em água peptonada $(0,1 \%)$ estéril. As sucessivas diluições foram inoculadas em placas de PCA $^{1}$ para determinação da contagem total de psicrotróficos. As placas foram incubadas por 10 dias a $7^{\circ} \mathrm{C}$ e as contagens realizadas em placas contendo entre 30 e 300 colônias [21].

A atividade proteolítica foi analisada pelo método de hidrólise de gelatina solúvel [15]. Alíquotas de $100 \mu \mathrm{L}$ foram diluídas em $100 \mu \mathrm{L}$ de tampão acetato de amônio pH 5,5. Adicionou-se $10 \mu \mathrm{L}$ de cisteína $0,1 \mathrm{M}$ e após 5 min a reação foi iniciada pela adição de $300 \mu \mathrm{L}$ de solução $10 \mathrm{mg} / \mathrm{mL}$ de gelatina. ${ }^{2} \mathrm{~A}$ mistura foi incubada por $60 \mathrm{~min}$, a $37^{\circ} \mathrm{C}$, adicionou-se $660 \mu \mathrm{L}$ de isopropanol, e os tubos foram incu-bados por $15 \mathrm{~min}$, em banho de gelo. As amostras foram centrifugadas por $10 \mathrm{~min}$ a 10.000 $g$ e os sobrena-dantes resultantes removidos com uma pipeta Pasteur. A absorbância a $280 \mathrm{~nm}$ foi determinada em espec-trofotômetro Hitachi U1100. Uma unidade de atividade enzimática representa a quantidade de enzi-ma necessária para modificar $\mathrm{A}_{280}$ em $0,01 / \mathrm{h}$ a $37^{\circ} \mathrm{C}$.
A associação entre contagem de bactérias psicrotróficas e atividade proteolítica das populações em amostras de leite cru refrigerado foi testada pela correlação de Pearson. Diferenças entre dois tipos de populações foram analisadas através do teste $t$ para amostras simples. A análise de variância foi utilizada para determinar diferenças entre populações de bactérias psicrotróficas e atividade proteolítica em diferentes amostras. A análise estatística foi realizada com o algoritmo Origin $5.0^{3}$.

\section{RESULTADOS}

Os valores médios de bactérias psicrotróficas cultiváveis em PCA foi entre 6,0 e 6,5 log UFC/mL para amostras obtidas nos diferentes laticínios (Tabela 1). As amostras não apresentaram diferenças significativas nos níveis de contagens de populações de bactérias psicrotróficas (análise de variância de medidas repetidas; $F=0,668 ; P=0,515$ ). Não foram observadas diferenças significativas nos níveis de bactérias psicrotróficas entre os dois laticínios (teste $t: t=-1,184 ; P=0,243$ ).

Os valores médios de atividade proteolítica variaram entre 3 e $12 \mathrm{U} / \mathrm{mL}$ (Tabela 1). Observou-se grande variabilidade na atividade proteolítica, algumas amostras apresentaram elevada atividade, enquanto outras mostraram atividade muito baixa. As amostras apresentaram diferenças significativas nos valores médios de atividade proteolítica (análise de variância de medidas repetidas; $F=13,132 ; P=1,04 \mathrm{x}$ $10^{-5}$ ). A comparação entre a atividade proteolítica detectada em amostras de leite cru indicou que existem diferenças significativas entre os diferentes laticínios

Tabela 2. Análise da correlação entre atividade proteolítica e contagens de psicrotróficos* em leite cru refrigerado obtido de dois laticínios do Estado do Rio Grande do Sul.

\begin{tabular}{lccc}
\hline Laticínio & $\boldsymbol{n}$ & $\boldsymbol{r}$ & $\boldsymbol{P}$ \\
\hline L1 & 50 & $5,46 \times 10^{-5}$ & 0,999 \\
L2 A & 20 & 0,213 & 0,368 \\
L2 B & 20 & 0,246 & 0,296
\end{tabular}

*Os valores de atividade proteolítica e contagem de bactérias psicrotróficas das 50 amostras do silo de armazenamento do laticínio L1, 20 amostras do tanque isotérmico de caminhões (A) e 20 amostras do silo de armazenamento (B) do estabelecimento L2, foram submetidos teste de correlação de Pearson. Os parâmetros $r$ e $P$ foram calculados através do algoritmo Origin 5.0. 

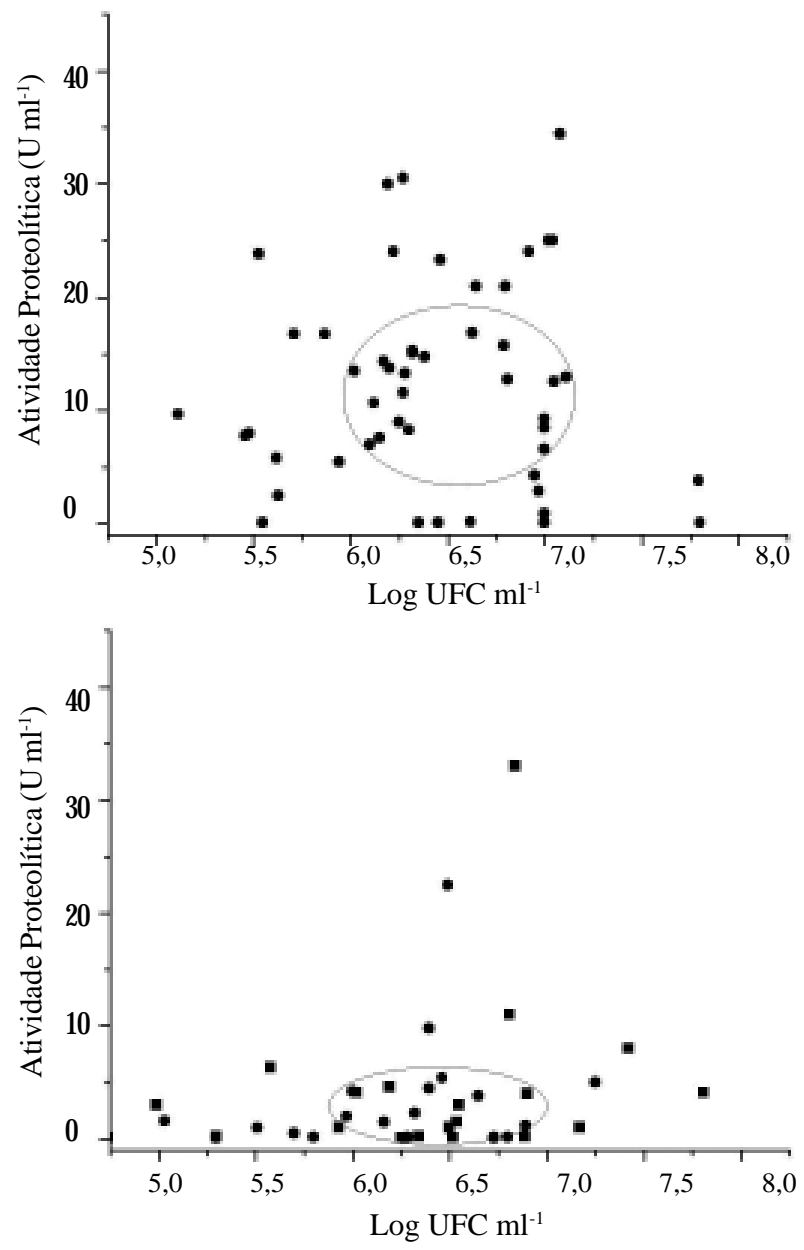

Figura 1. Correlação entre atividade proteolítica e contagens totais de psicrotróficos em amostras de leite cru refrigerado originado do laticínio L1 (A) e L2 (B). (•) Amostras de silos de armazenamento, (ש) amostras do tanque isotérmico de caminhões.

(teste $t: t=-8,508 ; P=2,01 \times 10^{-10}$ ), com atividade proteolítica superior nas amostras provenientes do laticínio L1.

A distribuição da atividade proteolítica detectada nas amostras de leite cru refrigerado em relação às contagens de bactérias psicrotróficas das respectivas amostras pode ser visualizada na Figura 1. Não foi observada uma correlação significativa entre a população de psicrotróficos e atividade proteolítica nas amostras estudadas (Tabela 2). Embora a correlação seja negativa, pode ser observado que a maioria das amostras apresentaram contagens entre 6 e $7 \log \mathrm{UFC} / \mathrm{mL}$. Agrupando essas amostras em função da atividade proteolítica, podem ser formados clusters incluindo 40\% das amostras do laticínio L1 e 50\% das amostras do laticínio L2 (Figura 1).

\section{DISCUSSÃO}

A contaminação dos produtos lácteos por bactérias psicrotróficas pode originar-se do suprimento de água de qualidade inadequada, deficiências de procedimentos de higiene e mastite [20]. Estes microorganismos mantêm sua capacidade de multiplicação em condições de refrigeração e tendem a se tornar predominantes na microbiota do leite cru $[9,14]$. Isto sugere que a refrigeração do leite cru, até a chegada na unidade de processamento, prevista na legislação de no máximo $7^{\circ} \mathrm{C}$ [2], não é suficiente para a manutenção da qualidade microbiológica da matériaprima dependendo de quanto tempo que esse leite fique submetido a essa condição. Uma contaminação inicial elevada do leite pode promover o aumento da população para 8-9 $\log \mathrm{UFC} / \mathrm{mL}$, conferindo prejuízos econômicos à indústria de laticínios, o que torna a situação do leite que chega até ao laticínio com contagens elevadas bastante preocupante.

As contagens médias observadas neste trabalho foram similares às descritas por Pinto et al. [22], que encontraram contagem média de bactérias psicrotróficas de $6 \log \mathrm{UFC} / \mathrm{mL}$ no leite cru refrigerado. Contagens elevadas de bactérias psicrotróficas no leite bovino têm sido relatadas em diferentes regiões do Brasil (Tabela 3). Estes resultados são preocupantes, pois, quando o número de psicrotróficos atinge contagens superiores a $6 \log \mathrm{UFC} / \mathrm{mL}$, sugere-se a produção significativa de enzimas termorresistentes responsáveis por alterações como a gelatinização do leite UAT, além do desenvolvimento de sabor residual no leite pasteurizado [6,23].

Bactérias psicrotróficas, por si não representam um problema muito sério para indústria, pois são eliminadas pelo tratamento térmico, entretanto as enzimas produzidas e secretadas por estes micro-organismos apresentam efeitos deteriorantes. Tais enzimas são freqüentemente muito estáveis ao calor e resistentes ao processo térmico convencional usado no leite $[16,18]$. Uma ampla gama de problemas de qualidade de produtos lácteos pode estar associada à ação de proteases e lipases de origem microbiana, como alteração de sabor e odor do leite, perda de consistência na formação do coágulo para fabricação de queijo e gelatinização do leite UAT [8,33].

A atividade proteolítica das amostras de leite cru refrigerado apresentou uma ampla variação, mesmo assim foram observadas diferenças entre as médias dos diferentes laticínios. Muitos relatos da atividade 
Tabela 3. Contagens de micro-organismos psicrotróficos em amostras de leite bovino obtidas em diferentes regiões do Brasil.

\begin{tabular}{|c|c|c|c|c|}
\hline Tipo de leite & Local & Amostras & $\begin{array}{l}\text { Psicrotróficos } \\
(\log \text { UFC/mL) }\end{array}$ & Referências \\
\hline Cru refrigerado & $\mathrm{RS}$ & 70 & 5,0 a 7,62 & Este estudo \\
\hline Cru & $\mathrm{RS}$ & 120 & 5,52 (várias > 8,0) & [28] \\
\hline Cru refrigerado em tarros & MG & 5 & $>6,0$ & {$[1]$} \\
\hline Cru refrigerado a granel & MG & 5 & $>5,0$ & {$[1]$} \\
\hline $\mathrm{Cru}$, pasteurizado desnatado e UAT & $\mathrm{RS}, \mathrm{GO}, \mathrm{SP}$ & 18 & 6,15 a 7,94 & [29] \\
\hline Cru refrigerado & $\mathrm{ES}$ & 20 & 4,04 a 7,59 & {$[11]$} \\
\hline Cru transportado em temperatura ambiente & $\mathrm{SC}$ & 125 & 3,4 a 8,23 & {$[25]$} \\
\hline Cru transportado refrigerado & $\mathrm{SC}$ & 125 & 2,3 a 10,0 & {$[25]$} \\
\hline Cru & MG & 50 & 4,5 a 7,45 & {$[26]$} \\
\hline Pasteurizado tipo $\mathrm{C}$ & MG & 50 & 2,48 & {$[26]$} \\
\hline Pasteurizado tipo $\mathrm{C}$ & $\mathrm{RJ}$ & 43 & 2,18 a 5,15 & {$[5]$} \\
\hline Pasteurizado tipo $\mathrm{C}$ & SP & 31 & 2,83 & {$[24]$} \\
\hline Pasteurizado tipo B & SP & 31 & 2,31 & {$[24]$} \\
\hline
\end{tabular}

proteolítica de bactérias psicrotróficas do leite baseiam-se na formação de halos de proteólise em placas de agar, embora alguns autores descrevam a quantificação dessa atividade proteolítica [3,17]. Entretanto, as metodologias para determinação de proteólise no leite geralmente são distintas e não permitem uma comparação direta dos resultados obtidos. A quantificação da atividade proteolítica de 52 amostras de leite cru obtidas na Índia revelou que a proteólise aumentou durante o armazenamento a $4^{\circ} \mathrm{C}$ e a $7^{\circ} \mathrm{C}$, mas não a $2^{\circ} \mathrm{C}$ [17]. No entanto, não se estabeleceu uma relação entre atividade proteolítica e contagens de bactérias psicrotróficas.

Embora o potencial deteriorante das proteases de bactérias psicrotróficas seja reconhecido, não existe uma correlação direta entre contagens de psicrotróficos e atividade proteolítica. Isto sugere que a composição da microflora de bactérias psicrotróficas do leite cru tenha um papel importante no desenvolvimento da proteólise. Algumas espécies de micro-organismos psicrotróficos seriam os principais responsáveis pela produção de enzimas termorresistentes. Neste sentido, espécies de Pseudomonas que produzem metaloproteases extracelulares termorresistentes têm sido associadas à degradação de proteínas do leite $[8,9,14,19]$. A ação das proteases de psicrotróficos é distinta entre as frações protéicas do leite. A K-caseína é a caseína mais susceptível à ação dessas enzimas, sendo que as proteínas do soro do leite são resistentes ao ataque das proteases [13]. A hidrólise da K-caseína desestabiliza as micelas, que coagulam, e esta alteração bioquímica é associada a gelatinização do leite UAT.

A gelatinização constitui-se em um dos principais problemas que afetam a qualidade do leite UAT. $\mathrm{O}$ processo UAT promove o aumento da viscosidade do leite, mas não a sua coagulação, já que o tempo de aquecimento é curto. Durante o período de armazenamento, a viscosidade do leite aumenta, até a formação do gel (gelatinização), indicando que o produto não está mais apto para o consumo [32]. Alguns pesquisadores acreditam que o fenômeno de gelatinização é induzido, inicialmente, pela ação de enzimas (proteases) termorresistentes presentes, naturalmente, no leite e/ou provenientes de bactérias, principalmente do grupo dos psicrotróficos. Estas enzimas apresentam a capacidade de degradar as caseínas e promover a agregação das micelas do leite $[10,12]$.

As proteases microbianas são ainda responsáveis pelo desenvolvimento de sabor residual no leite pasteurizado, amargor no leite UAT, e pela deficiência de determinados processos na produção de queijos, como a perda de rendimento e aparecimento de defeitos [6,30]. 


\section{CONCLUSÃO}

As amostras de leite obtidas de dois laticínios do RS apresentaram contagens de bactérias psicrotróficas similares ao observado por outros autores em diferentes regiões do Brasil. A presença de contagens elevadas de psicrotróficos no leite evidencia a existência de falhas em procedimentos de manipulação e higienização, podendo comprometer a qualidade e diminuir a vida de prateleira do produto final. A falta de correlação entre as contagens de psicrotróficos e a atividade proteolítica indica que o fenômeno da proteólise está principalmente associado a linhagens específicas de bactérias psicrotróficas com elevada capacidade de proteólise. A produção de enzimas hidrolíticas termorresistentes por bactérias psicrotróficas pode ocasionar alterações indesejáveis no leite UAT, como a gelatinização e o desenvolvimento de sabor amargo.

Agradecimentos. Os autores agradecem a CAPES-PICDT e ao CNPq pelas bolsas concedidas.

\section{NOTAS INFORMATIVAS}

${ }^{1}$ Mast Diagnostics, Merseyside, UK.

${ }^{2}$ Sigma, St. Louis, USA.

${ }^{3}$ Microcal Software, Northampton, USA.

\section{REFERÊNCIAS}

1 Antunes V.C., Siqueira Junior W.M., Valente P.P., Barros A.P., Conde C.B.C, Rosa R., Bertoldi M.C., Saraiva C. \& Ferreira C.L.L.F. 2002. Contagem total de microrganismos mesófilos e de psicrotróficos no leite cru e pasteurizado, transportado via latão ou granelizado. Revista do Instituto de Laticínios Cândido Tostes. 57: 198-201.

2 Brasil. 2002. Ministério da Agricultura, Pecuária e Abastecimento. Departamento de Inspeção de Produtos de Origem Animal. Instrução Normativa n$^{\circ} 51$ de 18 de setembro de 2002. Coleta de leite cru refrigerado e seu transporte a granel. Diário Oficial da República Federativa do Brasil. Brasília. 172, 8-13, 20 de setembro. Seção I.

3 Burdová O., Baranová M., Lauková A., Rözanska H. \& Rola J.G. 2002. Hygiene of pasterurized milk depending on psychrotrophic microorganisms. Bulletin of the Veterinary Institute Pulawy. 46: 325-329.

4 Chen L., Daniel R.M. \& Coolbear T. 2003. Detection and impact of protease and lipase activities in milk and milk powders. International Dairy Journal. 13: 255-275.

5 Cordeiro C.A.M., Carlos L.A. \& Martins M.L.L. 2002. Qualidade microbiológica de leite pasteurizado tipo C, proveniente de micro-usinas de Campos dos Goytacazes, RJ. Higiene Alimentar. 16: 41-44.

6 Costa L.M., Gómez M.F., Molina L.H. \& Romero, A. 2002. Purificación y caracterización de proteasas de Pseudomonas fluorescens y sus efectos sobre las proteínas de la leche. Archivos Latinoamericanos de Nutrición. 52: 1-13.

7 Cousin M.A. 1982. Presence and activity of psychrotrophic microrganisms in milk and dairy products: a review. Journal of Food Protection. 45: 172-207.

8 Datta N. \& Deeth H.C. 2001. Age gelation of UHT milk - a review. Food and Bioproducts Processing. 79: 197-210.

9 Eneroth A., Ahrné S. \& Molin, G. 2000. Contamination routes of Gram-negative spoilage bacteria in the production of pasteurized milk, evaluated by randomly amplified polymorphic DNA (RAPD). International Dairy Journal. 10: 325-331.

10 Famelart M.H., Tomazewski J., Piot M. \& Pezennec, S. 2004. Comprehensive study of acid gelation of heated milk with model protein systems. International Dairy Journal. 14: 313-321.

11 Feijó L.D., Pinheiro C.A., Silva A.C.O., Cerqueira M.M.O.P., Souza M.R. \& Pena C.F.A.M. 2002. Caminhões de Coleta a Granel: Monitoramento da qualidade do leite, da higienização do mangote e da superfície do caminhão tanque. Revista do Instituto de Laticínios Cândido Tostes. 57, 285.

12 Fox P.F. \& Kelly A.L. 2006. Indigenous enzymes in milk: Overview and historical apects. International Dairy Journal. 16: $500-516$.

13 Gaucher I., Mollé D., Gagnaire V. \& Gaucheron F. 2008. Effects of storage temperature on physico-chemical characteristics of semi-skimmed UHT milk. Food Hydrocolloids. 22: 130-143.

14 Hantsis-Zacharov E. \& Halpern M. 2007. Culturable psychrotrophic bacterial communities in raw milk and their proteolytic and lipolytic traits. Applied and Environmental Microbiology. 73: 7162-7168.

15 Jones B.L., Fontanini D., Jarvinen M. \& Pekkarinen A. 1998. Simplified endoproteinase assays using gelatin or azogelatin . Analytical Biochemistry. 263: 214-220.

16 Koka R. \& Weimer B.C. 2000. Isolation and characterization of a protease from Pseudomonas fluorescens RO98. Journal of Applied Microbiology. 89: 280-288. 
17 Kumerasan G., Annalvilli R. \& Sivakumar K. 2007. Psychrotrophic spoilage of raw milk at different temperatures of storage. Journal of Applied Science Research. 3: 1383-1387.

18 Martins M.L., Araújo E.F., Moraes C.A., Mantovani H.C. \& Vanetti M.C.D. 2003. Diversidade genética de bactérias psicrotróficas proteolíticas isoladas de leite cru granelizado. Revista do Instituto de Laticínios Cândido Tostes. 58: 54-60.

19 Martins M.L,Araújo E.F., Mantovani H.C. \& Moraes C.A. 2005. Detection of the apr gene in proteolytic psychrotrophic bacteria isolated from refrigerated raw milk. International Journal of Food Microbiology. 102: 203-211.

20 Murphy S.C. \& Boor K.J. 2000. Trouble-shooting sources and causes of high bacteria counts in raw milk. Dairy Food and Environmental Sanitation. 20: 606-611.

21 Oliveira J.S. \& Parmelee C.E. 1976. Rapid enumeration of psychrotrophic bacteria in raw and pasteurized milk. Journal of Milk Food Technology. 39: 269-272.

22 Pinto C.L.O., Cardoso R.R. \& Vanetti M.C.D. 2004. Bactérias psicrotróficas proteolíticas e potencial determinador a temperaturas de refrigeração. Revista do Instituto de Laticínios Cândido Tostes. 59: 110-117.

23 Pinto C.L.O., Martins M.L. \& Vanetti M.C.D. 2006. Qualidade microbiológica de leite cru refrigerado e isolamento de bactérias psicrotróficas proteolíticas. Ciência e Tecnologia de Alimentos. 26: 645-651.

24 Roque R.A., Schumacher S.S.P. \& Paiva P.C. 2003. Quantificação de microrganismos psicrotróficos em leites pasteurizados tipos B e C, comercializados na cidade de São Paulo - SP. Higiene Alimentar. 17: 59-68.

25 Santos D. \& Bergmann G.P. 2003. Influência da temperatura durante o transporte sobre a qualidade microbiológica do leite cru. III-psicrotróficos. Higiene Alimentar. 17: 86-91.

26 Santos E.M.P., Cerqueira M.M.O.P., Silva A.C.O., Souza M.R. \& Pena C.F.A.M. 2002. Enumeração da microbiota psicrotróficos em leite. Higiene Alimentar. 16: 25-34.

27 Santos M.V. \& Laranja F.L.F. 2001. Importância e efeito de bactérias psicrotróficas sobre a qualidade do leite. Higiene Alimentar. 15: 13-19.

28 Schimitt A., Durr J.W. \& Soares, J. 2002. Contagens de mesófilos e de psicrotróficos em leite cru e de diferentes regiões do Rio Grande do Sul. Higiene Alimentar. 17: 181-186.

29 Silva P.H.F. 2003. Leite UHT: fatores determinantes para sedimentação e geleificação. Lavras, MG, UFLA. 2003. 147p. Tese (Doutorado em Ciências dos Alimentos) - Universidade Federal de Lavras.

30 Sørhaug T. \& Stephaniak L. 1997. Psychrotrophs and their enzymes in milk and dairy products: quality aspects. Trends in Food Science and Technology. 8: 35-41.

31 Tondo E.C., Lakus F.R., Oliveira F.A. \& Brandelli A. 2004. Identification of heat stable protease of Klebsiella oxytoca isolated from raw milk. Letters in Applied Microbiology. 38: 146-150.

32 Vasbinder A.J., Rollema H.S., BotA. \& Kruif C.G. 2003. Gelation mechanism of milk as influenced by pH and temperature, studied by the use of transglutaminase cross-linked casein micelles. Journal of Dairy Science. 86: 1556-1563.

33 Wiking L., First M.B., Larsen L.B. \& Nielsen J.H. 2002. Effects of storage conditions on lipolysis, proteolysis and sensory attributes in high quality raw milk. Milchwissenschaft. 57: 190-194. 